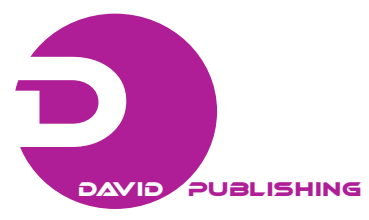

\title{
Wood Preservative Solutions for Creative and Sustainable Bridge Design and Construction
}

\author{
Ted John LaDoux \\ Western Wood Preservers Institute, Washington 98684, USA
}

\begin{abstract}
Timber bridges can provide an economical alternative to concrete and steel structures, particularly in rural areas where vehicle traffic is light to moderate. The wooden components of bridges have historically been preserved with either an oil type or waterborne preservative system to protect the wood from decay in order to maintain required performance standards for an extended period of time. The focus of this paper is to describe some of the key preservatives, research and case studies that support use of preserved wood, and some important steps to follow for the appropriate and safe use of preserved wood when the planned application will be in or over aquatic and wetland environments. A wealth of scientific information has been collected and analyzed that clearly suggests the use of preserved wood does not present a significant adverse effect on aquatic and wetland environments. This conclusion is based on two decades of empirical research and case study evaluating the environmental fate and effects of preserved wood, level of migration of contaminates into aquatic and marine environments, and the preserved wood environment. This is particularly true when risks are properly assessed on a project site, the appropriate preservative is selected and the wood is preserved to the Western Wood Preservers Institute's BMPs (best management practices), along with properly installing and maintaining the preserved material. To assist with the assessment process, peer-reviewed risk assessment models for 11 commonly used preservatives have been developed that provide for streamlined data entry by users and allow for evaluation of a structure above and below water. A companion preliminary screening level assessment tool is also available. When these measures are properly utilized engineers, biologists and other responsible officials can be confident that the service life of the preserved wood components will more than likely meet the required performance standards in an environmentally safe manner for up to 50 or more years on a majority of timber bridge projects.
\end{abstract}

Key words: Waterborne wood preservative, oil-type wood preservative, environmental risk assessment, best management practices.

\section{Introduction}

Why should you use preservative wood? Based on the fact wood degrades via non-living or living agents, or both at the same time, when wood is left unprotected from these agents there will be a significantly shorter life expectancy. This will continue to be a significant concern when using wood and for this very concern, preserved wood plays a key role in protecting wood from degradation while significantly extending the life expectancy. As a case study, the findings of 30 timber bridges that were inspected in the Pacific west ranging in age from 31 to 78 years were found to still be meeting or exceeding the required performance

Corresponding author: Ted John LaDoux, executive director, research fields: western north American pressure wood treating industry with emphasis on the production, use and environmental performance of wood products treated with chemical preservative systems. E-mail: ted@wwpinstitute.org. standards. Based on their individual conditions, these bridges were expected to satisfactorily perform for an additional 25-50 years.

These inspections were part of a US Federal Highway Administration and US Department of Agriculture, Forest Service Forest Products Laboratory national timber bridge survey project conducted between 2011 and 2013 [1]. In another cooperative study between the US Federal Highway Administration, the USDA Forest Products Laboratory and Aquatic Environmental Sciences, the environmental risks associated with timber bridges preserved with creosote, pentachlorophenol and chromated copper arsenate under worst-case conditions were evaluated. The study findings determined that no adverse biological effects were observed in either the invertebrate community or in laboratory bioassays at 
any of the bridges evaluated.

Researchers concluded the study results suggested that there would be minimal environmental risks associated with the level of preservatives lost from timber bridges. Researchers further concluded that many environmental risks could be minimized or eliminated by utilizing best management practices for construction and maintenance [2].

Knowing the environmental benefits of using preserved wood compared to alternative materials is also an important factor to consider when determining the type of material to use on a structure. This determination was made in a series of quantitative evaluations conducted by the Treated Wood Council on the environmental impacts associated with the national production, use and disposition of various preserved wood products compared to alternative materials.

As an example, a LCA (life cycle assessment) on ACQ (alkali copper quat)-treated lumber found that seven out of eight key environmental impact indicators required less total energy and less fossil fuel, had lower overall environmental impacts, and when reused for energy recovery in permitted facilities with appropriate emission controls, there would be further reduction of greenhouse gas levels in the atmosphere. The evaluation was conducted using LCA methodologies and followed ISO 14044 standards, as well as being peer-reviewed. A link to the summary of the ACQ-treated lumber LCA can be found in Ref. [3].

The use of wood preservatives is highly regulated by the US EPA (Environmental Protection Agency) under the FIFRA (Federal Insecticide, Fungicide and Rodenticide Act). All wood preservatives are required to undergo a rigorous registration and re-registration process. The EPA considers wood preservative systems as antimicrobial pesticides and requires that the pesticides must be supported with thorough scientific review and analysis, as well as show they can be used without causing undue adverse effects to human health or the environment. Under federal law a preserved wood product is not considered to be a pesticide and therefore not regulated by FIFRA.

Due to increased concern by the scientific community and the general public over the general use of all chemicals beginning in the latter part of the 20th century, the wood preserving industry began reviewing what scientific literature existed on the environmental performance of preserved wood in aquatic and marine environments. This review found that very little research had been conducted on the subject, leading the wood preserving industry to work independently and in cooperation with federal and state agencies in conducting numerous research projects and case studies. This resulted in numerous research papers and reports written on the subject.

Even though research continues, the results of past research represent the most authoritative on what is known today about the environmental effects of using preservative wood. This information gives proponents a unique ability to conservatively predict the level of potential risks on a project site basis and help support decisions to use, or not use, preservative wood, or to identify circumstances where mitigating measures may be necessary to further minimize or eliminate potential environmental risks.

\section{Five Steps to Appropriate Use of Preservative Wood}

Because most types of timber bridges - such as pedestrian, auto or railway-cross some form of water body or drainage, they pose varying degrees of environmental risk or required protection when constructed or maintained. For this reason, it is important to have guidance in understanding the science behind wood preservative systems and how to select and manage the use of preserved wood to ensure the desired performance while minimizing the potential risk for any adverse environmental impacts. The process begins at project conception and follows all the steps through installation and maintenance.

The following five basic steps are recommended 
when planning use of preserved wood in aquatic and wetland environments (fresh and salt water):

(1) selecting the proper preservative;

(2) environmental considerations and evaluations;

(3) specifying best management practices;

(4) requiring quality assurance and certification;

(5) following basic handling, installation and maintenance guidelines.

\subsection{Selecting the Proper Preservative}

To make sure the appropriate preserved wood product is selected, it is important to fully understand how to identify and specify the appropriate wood preservative system based on the desired species and existing environment on a project site. Some good resources available that provide helpful information are the wood preservation section in the USDA Forest Products Laboratory's Wood Handbook, Chapter 15: Wood Preservation-General Technical Report (FPL-GTR-190-2010) found in Ref. [4]; WWPI (Western Wood Preservers Institute) Guidance Documents found in Ref. [5]; WWPI Treated Wood Guide Smartphone Application (iOS and Android) found in Ref. [6]; and the AWPA (American Wood Protection Association) Book of Standards-Use Category System Standard U1, Sections 3-5 found in Ref. [7].

While the AWPA Book of Standards identifies 27 different wood preservative systems, only seven are commonly used to preserve material designated for use in aquatic and wetland environments either in and/or over fresh and salt water. There are a few other preservative systems available, but they will not be addressed in this paper as they are not commonly used in the western region of the United States. In addition, there are other proprietary formulations available that are often selected for aesthetic purposes, but are also not discussed.

The seven commonly available preservatives for use in aquatic and wetland environments can be broken down into two general categories-waterborne and oil-type preservative systems.

\subsubsection{Waterborne Preservative Systems}

Waterborne systems are considered inorganic preservatives and are characterized by the fact that water is the primary carrier of the preservative chemical. In these systems the chemicals are precipitated into the wood substrate and become attached to the wood cells, minimizing migration once the chemical is stabilized or fixed to the wood cells. In general, all waterborne preservatives perform basically the same way. They also leave a dry and paintable surface. The primary environmental concern with these preservatives is the potential environmental effect the loss of copper will have on the specific project environment when placed into service. For this reason it is critical to conduct a screening level assessment for each project site.

The three main waterborne systems or groups used in aquatic and wetland environments are:

- CCA (chromated copper arsenate)-Since 2004, CCA only has been available for use in preserving commercial and/or industrial type wood products. While CCA preserved wood products are readily produced throughout the US, use of these products near, in or over bodies of water are largely discouraged or prohibited in many western states by permitting agencies, even though it has been demonstrated that the environmental risks are minimal. This is primarily a result of perceived concerns about the toxicity of arsenic in this preservative.

In addition, because coastal Douglas fir is usually the preferred wood species for many commercial and industrial applications, CCA is not recommend for treating this species and other hard to treat species. The opposite is true for many other parts of the US, like in the southeastern states, where the preferred species Southern Yellow Pine is easier to treat and where CCA preserved products are considered environmentally friendly. Also, CCA is the only preservative system that has testing technology (chromotropic acid test) that can determine whether fixation of the preservative 
has been achieved in the wood cells;

- ACZA (ammoniacal copper zinc chromate)-Under the trade name Chemonite ${ }^{\circledR}$, ACZA is an ideal preservative to use for hard to treat species like coastal Douglas fir. Because of this quality and its environmental record, ACZA is normally the preservative of choice to treat coastal Douglas fir and other western species for uses such as piling, bulkhead and bracing that will be immersed or come into contact with fresh or salt water. In some local areas of the West, use of ACZA products is restricted because of the perceived environmental risk associated with short-term migration of the preservative from the wood. These restrictions may include additional mitigating measures, such as wrapping or coating, to help stop or minimize the loss of preservative from the product. ACZA is also commonly used in a variety of above water applications;

- ACQ (alkaline copper quat) and CA (copper azole)_-These preservatives are widely used throughout the US in a variety of residential, commercial and certain agricultural applications and are often thought of as "general use" preservatives. Both ACQ and CA preserved wood products perform basically the same with some minor product application differences. They are both commonly used to preserve lumber and timbers for above and in fresh water or subject to some brackish or saltwater splash. The exception is that ACQ preserved round and sawn wood piling also can be used for land and in freshwater applications. As with ACZA, there is an environmental concern by some permitting agencies over the perceived environmental effects the loss of copper from these preservatives may have on the specific project environments. However, with some exceptions, products preserved with ACQ and CA are generally viewed favorably for general use in or above freshwater or near saltwater applications.

\subsubsection{Oil-Type Preservative Systems}

Oil-type preservatives are organic preservatives characterized by the fact that they are $100 \%$ active
(Creosote) or dissolved in an oil-based solvent. These mixtures fill or coat the wood cell walls during treatment.

The three primary oil-type systems used in aquatic and wetland environments are:

- Creosote-This is a coal tar-based wood preservative and when used as a preservative it only can be manufactured by the distillation of tar obtained from coal. It typically has some odor and is not paintable. Primary use is the treatment of industrial products such as railway ties, utility poles and crossarms, piling and timbers for bridges and other transportation structures. Creosote preserved wood can be used in a variety of applications requiring in-ground contact, or in and/or over fresh and salt water.

Creosote has a long history of being a very effective preservative and it is not uncommon to find marine piling and bridge structures today ranging in age from 50 to 90 years old still in good serviceable condition. Acceptance and use of creosote preserved material varies by region. For example, in Alaska and the southeastern states it is widely used for preserving a variety wood products, such as marine piling, dock structures, bulkheads, utility poles and bridges.

Creosote is extensively used to treat railway ties used by our nation's railroads, which represents approximately $95 \%$ of the creosote use today. In most of the western states, other than the railways, use is typically restricted to replacement of existing structures for maintenance purposes. In the states of New York and New Jersey all aquatic uses of Creosote-treated wood are prohibited. Creosote is not recommended for use in residential, industrial or commercial interiors (except for laminated beams or building components that are in ground contact) and where there may be frequent or prolonged contact with bare skin;

- PCP (pentachlorophenol)_-This preservative in a solid state is dissolved in petroleum oil either in diesel or fuel oil grades and light hydrocarbon solvents. PCP is diluted to approximately $5 \%$ to $10 \%$ in oil in order 
to be used in a preservative solution. Use of PCP is popular for preserving wood utility poles and crossarms, as well as solid wood and laminated timbers used in construction of buildings and bridges. PCP-preserved material in aquatic applications are restricted to above water structures in saltwater and in or above freshwater. Like creosote, PCP is not recommended for use in residential, industrial or commercial interiors except for laminated beams or building components that are in ground contact and where there may be exposure to frequent or prolonged contact with bare skin. PCP in light hydrocarbon solvents leaves a more natural appearance and may be specified where stain finish is desired;

- CuN (copper napthenate) - This preservative is different than the other copper-based preservatives in that the copper is reacted with naphthenic acid, a hydrocarbon by-product of crude oil processing. The $\mathrm{CuN}$ concentrate is diluted with fuel oil at treating plants to make the preservative solution. Unlike other oil-type preservatives, $\mathrm{CuN}$ is not a restricted pesticide. When CuN is applied, it is initially a light green color that diminishes over time due to weathering and often has an odor. There are odor neutralizers available that can be applied should odor be an issue.

After thorough drying CuN preserved wood can be painted or stained, but a stain-blocking primer or second topcoat is recommended for finishing to minimize the CuN treatment's discoloration of the finish. CuN is used to preserve a variety of products for industrial projects such as foot and auto bridges, as well as fence rails and posts, guardrail posts, railroad ties, utility poles, piling and outdoor recreational structures. Other than being restricted from use in brackish or salt water applications, CuN can be used to preserve a variety of wood materials for use near saltwater or in and above ground for freshwater applications.

In addition to the above referenced informational resources, many other factors will come into play when selecting the appropriate preservative system. Managers will likely weigh the economics, type of project, availability of wood species, aesthetics, environmental concerns and the permitting or approval process itself. These decisions will be influenced in part or whole by the permitting authority, existing laws, personal preference, organizational policy, professional knowledge and environmental conditions.

\subsection{Environmental Considerations and Evaluation}

In designing a project, the characteristics of various preserved wood products should be taken into consideration in relation to the purpose of the project and the environmental conditions at the project site. Products used in a heavy industrial applications, like a bridge used for motor vehicles, will be different from those used in a public structure such as a foot bridge or boardwalk. Similarly, the use of a moderate amount of preserved wood in a fast flowing river or stream is likely to pose a minimal risk; whereas, the use of large amounts of preserved wood in somewhat stagnant water may pose greater risks.

Nearly any material used in aquatic environments will introduce some degree of chemical and have an environmental effect if present in large enough concentrations. When specifically using the previously described wood preservatives, a certain amount of preservative will migrate from all these products, but typically for only a short period of time and entering the water column or sediment adjacent to the project area. For this reason, it is important to be able to evaluate the level of potential risk on a site specific basis to properly manage the risks. There are project situations where the use of preserved wood may be of significant environmental concern such as previously contaminated waters or very slow moving waters with no natural flushing. However, based on scientific studies and field results, 95\% of projects constructed today in some type of aquatic environment should not be significantly impacted from use of preserved wood when the risks are identified and managed.

To help biologists and project proponents of preservative wood, peer-reviewed risk assessment 
models are recognized by NOAA-Fisheries as being useful in evaluating the potential environmental effects. These assessment models are readily available to assist in determining the potential risks associated with a proposed project. A detailed discussion of the models and supporting information preservative wood can be used safely in aquatic environments when the risks are evaluated can be found in NOAA-Fisheries 2009 guide for treated wood, Use of Treated Wood Products in Aquatic Environments: Guidelines to West Coast NOAA Fisheries Staff for Endangered Species Act and Essential Fish Habitat Consultations in the Alaska, Northwest and Southwest Regions [8].

In addition to the risk assessment models, a companion Level One Screening Assessment tool based on the science used to develop the more robust risk assessment models also has been created to further assist in making evaluations of the environmental risks. This simplified assessment tool utilizing tables and some basic project site conditions was designed to easily make preliminary predictions on whether a more extensive risk assessment should be undertaken, or support a conclusion that there would be no significant environmental effect from using preserved wood on a project.

The risk assessment models are based on research of preservative loss rates from properly preserved wood and, when coupled with site-specific project environmental data such as water current speeds and background levels of metals and organics in the sediment, it allows users to predict the environmental response to any project design when preservative wood is used in and/or over an aquatic environment, including the use of multiple wood preservatives. For those interested in a detailed discussion on the science and model assumptions used, they can be found in a book published by the Forest Products Society titled Managing Treated Wood in Aquatic Environments [9].

Preserved wood has a long history of safe use in aquatic environments, with no published report describing any significant loss of biological integrity associated with its proper use when, again, the risks are first evaluated and the proper preservative is selected.

\subsection{Specifying the Best Management Practices}

Another key element available for managing risk whenever preservative wood products are planned for an aquatic environment is the specification of the WWPI (Western Wood Preservers Institute's) BMPs (Best Management Practices) for Use of Preservative Wood in Aquatic and Wetland Environments [10].

The BMPs are additional wood preserving guidelines for all individual or groups of preservative systems used to preserve wood designated for use in aquatic or wetland environments. The established guidelines are intended to further minimize the amount of potential chemical migration or movement from preserved wood material during the wood preserving process.

Specification of the BMPs gives specifiers another valuable environmental protection tool to use to assure preserved material used on a project site has been preserved with the minimal level of preservative needed for protection that meets AWPA standards while reducing the amount potentially available for migration or movement in to the environment.

Along with the additional processing requirements, BMPs are separate from and in addition to the AWPA standards. There is a shared responsibility between the specifier and treater to assure the level of preservative system application selected will meet the goal of minimizing the migration of the preservative into the environment.

\subsection{Providing Quality Assurance and Certification}

One of the benefits of specifying wood material be preserved according to the BMPs is that third-party independent inspection procedures and certification are in place to assure the material meets AWPA standards and the BMP guidelines.

To assure products meet the AWPA standards, it is 
important that the presence of a quality checkmark be present on all structural product labels or in a letter of certification should labeling not be present. The presence of the CheckMark logo (as shown in Fig. 1) is a quick and simple way of identifying whether the product material purchased has been inspected by an approved ALSC (American Lumber Standard Committee) third-party inspection agency authorized to assure compliance with AWPA standards.

Additionally, to assure material has been preserved in accordance with the BMP guidelines, certification should also be verified by an authorized ALSC third-party inspection agency by letter of certification or the presence of the WWPI BMP certification mark (as shown in Fig. 2) on the product or unit. Details on the quality assurance inspection procedures and requirements are incorporated as a separate chapter in the BMP document.

It is strongly recommended for the specifying agency and/or contractor and the selected supplier to review the project specifications and material requirements to assure the proper material will be produced to the desired standard and specification for the project, along with an understanding of the required quality assurance and certification. It is also advised, if practicable or customary for the wood preserving company, to be directly contacted to discuss the required

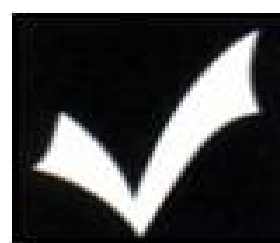

Check here for the mark of an ALSC accredited inspection agency

Fig. 1 Check mark symbol and identification of applicable accredited ALSC (American Lumber Standards Committee) treated wood inspection agency in box right of check mark.

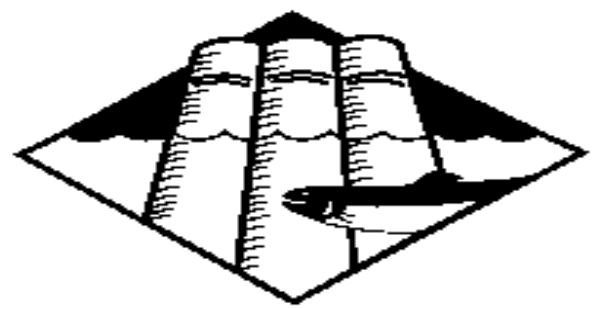

Fig. 2 BMP certification mark. specifications, including the environmental concerns for the project. Past experience has shown when a preservative product has not met the expectations of the purchaser, it has typically been the result of a breakdown in communications.

\subsection{Appropriate Handling, Installation and Maintenance}

One of the most critical times in the life of a project using preserved wood, in terms of environmental impacts, is during and immediately following construction. While use of a US EPA registered preservative treated to AWPA standards, along with specification of the BMPs will help assure minimal environmental impacts, there are several other actions that can be taken to further ensure the project is constructed and maintained in an environmentally safe manner during installation or maintenance of the structure.

Some suggested additional actions are as follows:

- To the degree possible, framing, sawing, cutting and drilling should be specified to be done prior to preserving the wood;

- Products should be inspected when they arrive on project site;

- Use containment measures when working over water to catch and collect cuttings, shavings and sawdust where necessary. Where practical, conduct additional fabrication work away from water and provide for collection of waste;

- All field cuts and drill holes created on project site should be field treated. Available treatments include Copper Napthenate, Outlast Q8 and Hollow Heart CB;

- Removal of old preserved wood structures for maintenance purposes or demolition can either be recycled for reuse, if suitable, or per federal and most state laws can be disposed as non hazardous or exempt hazardous waste in approved landfills;

- Routine inspection and timely maintenance is critical to extending the service life of a preserved wood structure. 
For further perspectives on using preserved wood in aquatic or wetland environments, read Guide for Minimizing the Effect of Preservative-Treated Wood on Sensitive Environments published by the USDA Forest Products Laboratory [11].

\section{Conclusions}

For over a century, the preserved wood has played an essential role in the economic prosperity and quality of life in North America. The use of preservative wood has been the preferred, time-proven, cost effective material of choice, used for the rail ties that carry our trains; the poles that carry communications and power; the bridges that cross our rivers and valleys carrying vehicles and foot traffic; the industrial and commercial structures serving businesses and communities; and the scenic and recreational structures enjoyed by millions of visitors.

Since the awakening of environmental awareness, including use of chemicals, by society in the second half of the 20th century, there have been numerous environmental laws adopted and the implementation of regulatory policies, in some cases unwritten polices, that restricted the use of some construction practices and material use in aquatic environments. As a result, this awakening also brought about greater scrutiny over the use of preserved wood products in aquatic and wetland environments.

Because of this emerging concern, the wood preserving industry undertook action to better understand the environmental effects of wood preservative systems on aquatic and wetland environments to improve how to determine the proper applications and assure they could be environmentally safe to use. For the past two decades, there has been progress in conducting research and studies in partnership with various governmental agencies, universities and the wood preserving industry to better understand the environmental performance and potential effects of using preserved wood in aquatic and wetland environments.
All the information presented in this paper represents the collective result of the research, case studies and technical analysis conducted to date on the environmental performance of preserved wood in aquatic and wetland environments. The scientific data collected also represent the most authoritative and comprehensive science available, which was critical in developing needed risk assessment models that conservatively predict environmental effects, as well as companion screening level assessment tools. The scientific data and economic analysis clearly support the use of preserved wood material as a cost-effective and environmentally safe solution for use on most bridge projects.

While there are no federal laws prohibiting use of preservative wood and only a few states with limited restrictions, there is a general bias against the use of any type of preservative wood material among some regulatory agencies and individual biologists responsible for enforcing the provisions of the Magnuson-Stevens Act-Essential Fish Habitat and the Endangered Species Act due to perceived detrimental environmental effects. However, the vast majority of empirical science is contrary to this viewpoint and clearly supports the use of preserved wood in most situations.

What is critical to know is that when the appropriate preservative system is selected, the potential environmental effects evaluated on a site specific basis and the WWPI BMPs are specified, the potential risks will be minimal and manageable for the environmentally safe use of preserved wood products in the majority of projects where use of preserved wood is desired. For this reason the goal is to make all the scientific studies and assessment tools readily available to public and private engineers, biologists and managers to help gain a better understanding of the underlying science and the importance of assessing the potential environmental effects on a project site.

Research on the environmental performance of preserved wood is ongoing to further validate the risk 
assessment models, improve best management practices and implement training programs to educate biologist, engineers and decision makers on use of available screening level assessment tools in order to broaden the knowledge and use of these tools so manager can make informed decisions.

\section{References}

[1] T. Williamson, L. Coomber, D. Strahl, Inspection of timber bridges in the pacific west (ID-150), in: International Conference on Timber Bridges, Las Vegas, 2013.

[2] K.M. Brooks, Assessment of the Environmental Effects Associated with Wooden Bridges Preserved with Creosote, Pentachlorophenol, or Chromated Copper Arsenate, Owner and Principal Scientist for Aquatic Environmental Sciences, Port Townsend, Washington, 2000.

[3] Life Cycle Assessment of ACQ Treated Lumber Summary[Online], www.wwpinstitute.org (accessed May 4, 2012).

[4] Wood Handbook (FPL-GTR-190-2010)[Online], http://www.fpl.fs.fed.us/products/publications/several_ pubs.php?grouping_id=100\&header_id=p (accessed Apr. 1, 2010).

[5] Western Wood Preservers Institute Guidance
Documents[Online], http://www.wwpinstitute.org/ aquatics.html\#guidance (accessed Sep. 11, 2012).

[6] WWPI Treated Wood Guide Smartphone Application (iOS and Android) [Online], www.wwpinstitute.org (accessed June 2013).

[7] American Wood Protection Association (AWPA) Book of Standards-Use Category System Standard U1 [Online], Sections 3-5, www.awpa.com (accessed Jan 1, 2014).

[8] Use of Treated Wood Products in Aquatic Environments: Guidelines to West Coast NOAA Fisheries Staff for Endangered Species Act and Essential Fish Habitat Consultations in the Alaska, Northwest and Southwest Regions[Online], 2009, http://wwpinstitute.org/documents/ NOAAFINALTWGUIDELINES_10.09.pdf (accessed Oct. 12, 2009).

[9] J.J. Morrell, K.M. Brooks, C.M. Davis, Managing Treated Wood in Aquatic Environments, Forest Products Society, 2011.

[10] Best Management Practices for Use of Preservative Wood in Aquatic and Wetland Environments (BMPs)[Online], Western Wood Preservers Institute, http://wwpinstitute.org/ documents/BMP_Revise_4.3.12.pdf (accessed Apr. 3, 2012).

[11] S.T. Lebow, M. Tippie, Guide for Minimizing the Effect of Preservative-Treated Wood on Sensitive Environments, USDA Forest Products Laboratory, Feb. 2001. 